\title{
An unusual case of neck hematoma and hypercalcemia
}

\author{
Lorenzo Porta, ${ }^{1}$ Roberto Ghezzi, ${ }^{1}$ Anna Chiara Cadonici, ${ }^{2}$ Paolo Dalino Ciaramella, ${ }^{3}$ \\ Chiara Martes, ${ }^{1}$ Adriano Basile, ${ }^{1}$ Andrea Bellone ${ }^{1}$ \\ ${ }^{1}$ Emergency Medicine Unit; ${ }^{2}$ Radiology Unit; ${ }^{3}$ Endocrinology Unit, ASST Grande Ospedale Metropolitano \\ Niguarda, Milan, Italy
}

\begin{abstract}
One of the most frequent cause of hypercalcemia is primary hyperparathyroidism, which can lead to systemic involvement and life-threatening conditions. We described a rare case of a parathyroid adenoma rupture with consequent bleeding and respiratory airway compression. An 84-year-old man presented to the emergency department complaining neck swelling and related dysphagia. A computer tomography of the neck revealed an extensive left lateral hematoma, and a neck ultrasonography evidenced a hemorrhagic parathyroid adenoma, later confirmed by a $99 \mathrm{mTc}-\mathrm{MIBI}$ scintigraphy. To date only 40 cases of ruptured parathyroid adenomas have been described in literature, however due to the possibility of massive bleeding and compression of the airways this diag-
\end{abstract}

Correspondence: Lorenzo Porta, Azienda Socio-Sanitaria Territoriale Grande Ospedale Metropolitano Niguarda, Piazza dell'Ospedale Maggiore 3, 20162 Milano (MI), Italy.

Tel.: +393470611396

E-mail: lorenzo.porta@ospedaleniguarda.it

Key words: Primary hyperparathyroidism; respiratory airway compression; adenoma rupture; hypercalcemia.

Contributions: All authors had access to the data. LP and RG were responsible for concept and design, drafting the manuscrip. AC was responsible for interpretation of the radiological imaging and critical revision. $\mathrm{PDC}$ was responsible for endocrinological support and critical revision. $\mathrm{CM}, \mathrm{AB}, \mathrm{AB}$ helped in the case management and critically revised the manuscript. All authors read and approved the final manuscript.

Conflict of interests: The authors declare no conflict of interest.

Availability of data and materials: Not applicable.

Ethics approval and consent to participate: Not applicable.

Consent for publication: Consent for publication was obtained.

Received for publication: 4 December 2020.

Revision received: 6 May 2021.

Accepted for publication: 27 May 2021.

This work is licensed under a Creative Commons Attribution 4.0 License (by-nc 4.0).

CCopyright: the Author(s), 2021

Licensee PAGEPress, Italy

Emergency Care Journal 2021; 17:9548

doi:10.4081/ecj.2021.9548 nosis should always be ruled out. The rupture of a parathyroid adenoma is a rare, but possibly life-threatening event due to airways compression and hemodynamic instability. Testing for hypercalcemia and hyperparathyroidism is mandatory to obtain a correct diagnosis.

\section{Introduction}

One of the most frequent cause of hypercalcemia is Primary Hyperparathyroidism (PHPT), a common endocrine disorder with prevalence estimates of 1-7 cases per 1000 adults, predominantly affecting elders and women. ${ }^{1-5}$ PHPT's symptoms are usually related to the hypercalcemia, ranging from dehydration, arrhythmias, loss of consciousness and coma; ${ }^{6,7}$ furthermore, mild to severe hyperparathyroidism can also lead to systemic consequences on primary target organs (osteoporosis, nephrolithiasis) as well as to psychiatric and cardiovascular diseases. We describe a rare case of primary hyperparathyroidism, starting with a parathyroid adenoma rupture and consequent bleeding: an extremely rare potentially life-threatening condition that may require emergency treatment due to respiratory airway compression.

\section{Case Report}

An 84-year-old man presented to the emergency department complaining swelling in the anterior cervical region of the neck and related dysphagia for two days, without any reported trauma to the neck. His past medical history was unremarkable, and he took no medication at home. At arrival, his vital signs were within the normal range; the neck appeared swollen, especially on the anterior left area, without either tirage or stridor. Blood exams indicated only slightly elevated levels of C-reactive protein (CRP - 3.9 $\mathrm{mg} / \mathrm{dL}$ - normal range $0-1 \mathrm{mg} / \mathrm{dL})$, White blood cells count $(14.52$ $10^{9} / \mathrm{L}$ - normal range 4.00-10.00 109/L), Calcium $(11.4 \mathrm{mg} / \mathrm{dL}-$ normal range: $8.8-10.1 \mathrm{mg} / \mathrm{dL})$ and D-dimer $(4.39 \mu \mathrm{g} / \mathrm{mL}-$ normal range $0-0.57 \mu \mathrm{g} / \mathrm{mL}$ ), with normal hematocrit, platelet count and INR. No renal or hepatic abnormalities were found. No abnormalities were detected at the EKG.

We performed a Computer Tomography (CT) of the neck and chest regions, which revealed an extensive left lateral cervical swelling $(8 \times 17.5 \times 8 \mathrm{~cm})$ with poorly defined margins, compatible with a hematoma with no signs of active bleeding. The swelling developed in the context of the distal third of the sternocleidomastoid muscle and it extended to the paravertebral musculature at the height of $\mathrm{C} 2-\mathrm{C} 4$. The formation encompassed the left common carotid artery, the origin of the subclavian vein and the external jugular vein, enveloping the left thyroid lobe. Hypopharynx, larynx, and trachea were deviated to the right with modest compression on the proximal third of the trachea. A roundish formation of 
uncertain meaning was present about $3 \mathrm{~cm}$ deeply in the left thyroid lobe; right thyroid lobe and isthmus were normal (Figures 1 and 2).

We treated the patient with a third-generation cephalosporin, intravenous steroids, hydration, and we admitted the patient to the emergency ward for observation and further investigations. During the hospitalization in the emergency ward, the patient slowly improved with a progressive reduction of the hematoma and recovery from the dysphagia. The blood examination confirmed increased level of Calcium $(12,8 \mathrm{mg} / \mathrm{dL})$ and PTH $(162 \mathrm{pg} / \mathrm{mL}$ normal range: $10-60 \mathrm{pg} / \mathrm{mL}$ ). To better identify the etiology of the bleeding, we required a neck ultrasonography, which evidenced that the aforementioned roundish formation was localized externally to the thyroid. Thus, due to the suspect of a hemorrhagic parathyroid adenoma, a 99 mTc-MIBI scintigraphy and SPECT$\mathrm{CT}$ was required, which demonstrated an abnormal uptake in the left lateral inferior parathyroid gland compatible with a parathyroid adenoma (Figure 3). The patient was then discharged in good clinical condition, with a prescription of Vitamin D supplements and Cinacalcet, and the indication of an outpatient follow-up to decide for the timing of the parathyroid removal. The discharge diagnosis was primary hyperparathyroidism caused by a parathyroid adenoma, with extracapsular rupture and hematoma of the neck.

\section{Discussion}

To date only nearly 40 cases of ruptured parathyroid adenomas have been described in literature. ${ }^{8-14}$ This clinical event should always be ruled out as a differential diagnosis in patients presenting with acute neck swelling, hematoma and pain because this condition could be fatal due to massive bleeding, compression of the airways and consequent respiratory failure.

Symptoms of a parathyroid adenoma rupture can differ, according to the localization of the parathyroid affected and the site of bleeding (intra or extra capsular). In fact, considering extracapsular ruptures, cervical hematomas are mostly characterized by dysphagia, dysphonia, hoarseness and either swelling or ecchymosis in the anterior regions of the neck. If the hematoma compresses the proximal airways, acute respiratory failure can develop, requiring emergency tracheostomy. Hematomas of the upper medi-

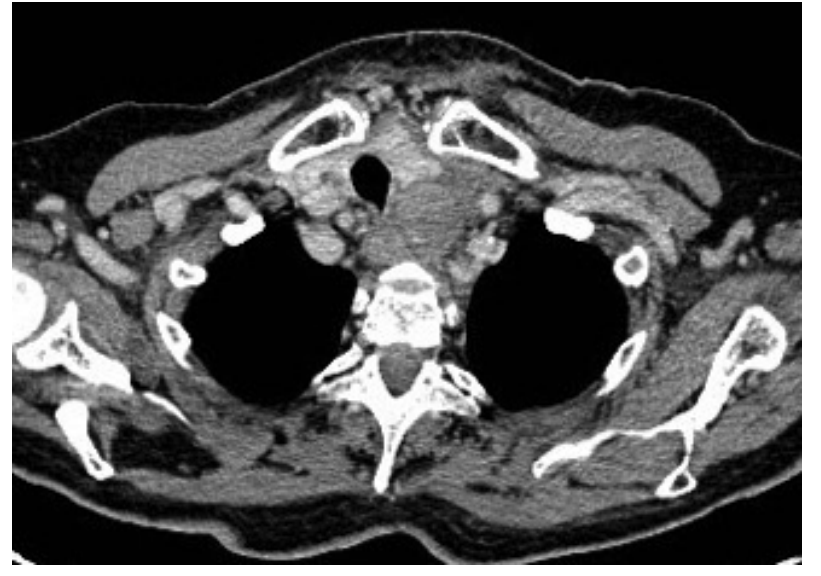

Figure 1. Computer Tomography (CT) of the neck and chest regions revealing an extensive left lateral cervical swelling $(8 \times 17.5 \times 8 \mathrm{~cm})$ with poorly defined margins, compatible with a hematoma with no signs of active bleeding.

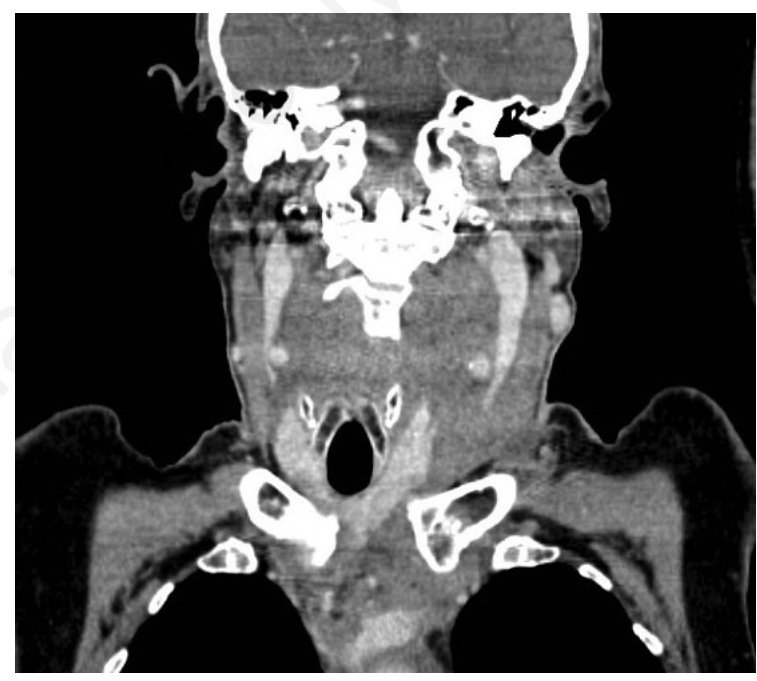

Figure 2. Computer Tomography (CT) of the neck and chest regions revealing an extensive left lateral cervical swelling $(8 \times 17.5 \times 8 \mathrm{~cm})$ with poorly defined margins, compatible with a hematoma with no signs of active bleeding.

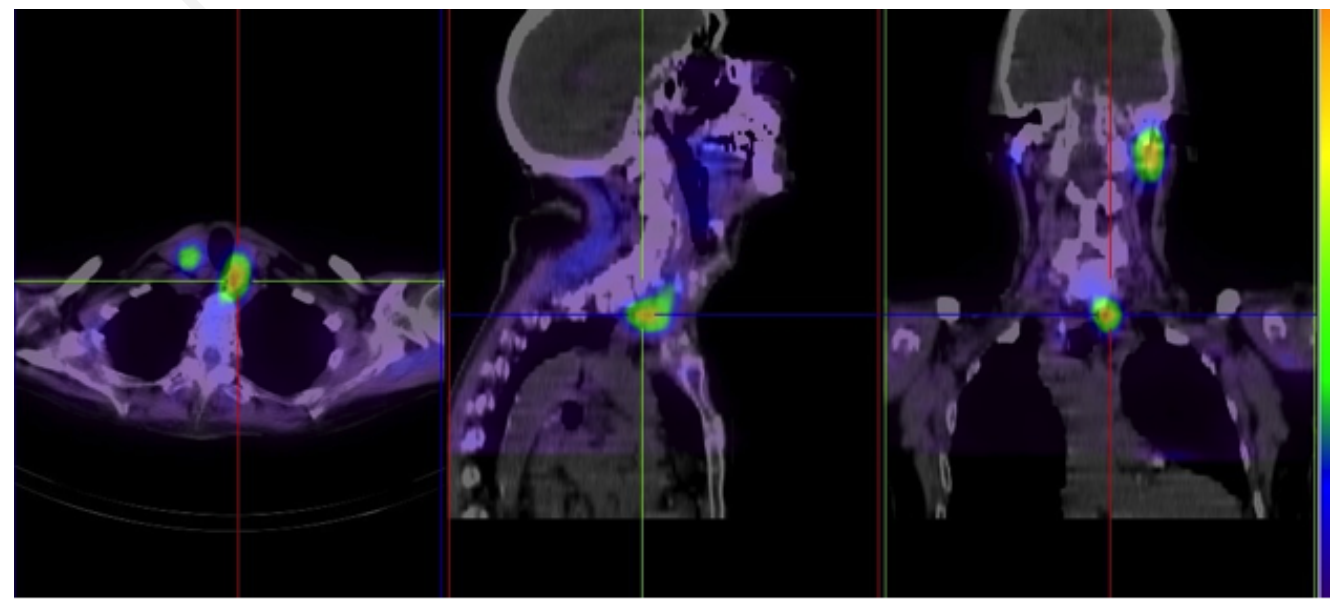

Figure 3. A $99 \mathrm{mTc}-\mathrm{MIBI}$ scintigraphy and SPECT-CT showing an abnormal uptake in the left lateral inferior parathyroid gland compatible with a parathyroid adenoma. 
astinum are characterized by cough, dyspnea, and respiratory distress. Compression of the large vessels of the neck might occur, leading to a life-threatening situation. Patients taking oral anticoagulants and with hemorrhagic diathesis have worse prognosis. ${ }^{15-19}$ In intracapsular ruptures, swelling and pain are the main two symptoms and the hyperparathyroidism might have a spontaneous remission by either infarction of or hemorrhage into the parathyroid adenoma. ${ }^{20}$

In our case, testing for hypercalcemia and related primary hyperparathyroidism was fundamental to diagnose the rupture of the adenoma as the cause of the unclear neck bleeding. Ultrasonography, CT, or MRI are useful tools to identify nodular or vascular structure of the neck (lymph nodes, thyroid or parathyroid lumps, hemangiomas, arteriovenous malformations) as the likely cause of bleeding. However, in case of suspected parathyroid adenomas, a sesta-mibi CT scan imaging is needed to confirm the localization, which could be performed after 4 weeks from the hemorrhagic event to allow the absorption of the hematoma. ${ }^{21,22}$ The optimal timing for the excision of the tumor remains controversial, however Chaffanjon et al. proposed that it should be performed at least 3 months after the hemorrhagic episode, if the patient does not required an emergency treatment. ${ }^{8}$

\section{Conclusions}

The rupture of a parathyroid adenoma is a rare but possibly life-threatening event due to airways compression and hemodynamic instability. Testing for hypercalcemia and hyperparathyroidism is mandatory to obtain a correct diagnosis in the emergency department.

\section{References}

1. Yeh MW, Ituarte PH, Zhou HC, et al. Incidence and prevalence of primary hyperparathyroidism in a racially mixed population. J Clin Endocrinol Metab 2013;98:1122-9.

2. Adami S, Marcocci C, Gatti D. Epidemiology of primary hyperparathyroidism in Europe. J Bone Miner Res 2002;17: N18-N23.

3. Christensson T, Hellström K, Wengle B, et al. Prevalence of hypercalcaemia in a health screening in Stockholm. Acta Med Scand 1976;200:131-7.

4. Wermers RA, Khosla S, Atkinson EJ, et al. The rise and fall of primary hyperparathyroidism: a population-based study in Rochester, Minnesota, 1965-1992. Ann Intern Med 1997; 126:433-40.

5. Yu N, Donnan PT, Murphy MJ, Leese GP. Epidemiology of primary hyperparathyroidism in Tayside, Scotland, UK. Clin Endocrinol 2009;71:485-93.

6. Kovacs KA, Gay JD. Remission of primary hyperparathy- roidism due to spontaneous infarction of a parathyroid adenoma. Case report and review of the literature. Medicine 1998;77:398-402.

7. Weber AL, Randolph G, Aksoy FG. The thyroid and parathyroid glands. CT and MR imaging and correlation with pathology and clinical findings. Radiol Clin N Am 2000;38:1105-29.

8. Chaffanjon PCJ, Chavanis N, Chabre O, Brichon PY. Extracapsular Hematoma of the Parathyroid Glands. World J Surg 2003;27:14-7.

9. Yoshimura N, Mukaida H, Mimura T, et al. A case of an acute cervicomediastinal hematoma secondary to the spontaneous rupture of a parathyroid adenoma. Ann Thorac Cardiovasc Surg 2014;20:816-20.

10. An L, Ji T, Li L. Diffuse hematoma caused by spontaneous rupture of a parathyroid adenoma: a case report. Braz J Otorhinolaryngol 2020;86:48-50.

11. Merante-Boschin I, Fassan M, Pelizzo MR, et al. Neck emergency due to parathyroid adenoma bleeding: a case report. J Med Case Rep 2009;3:7404.

12. Shinomiya H, Otsuki N, Takahara S-I, et al. Parathyroid adenoma causing spontaneous cervical hematoma: two case reports. BMC Res Notes 2015;8:726.

13. Rehman HU, Markovski M, Khalifa A. Spontaneous cervical hematoma associated with parathyroid adenoma. CMAJ 2010;182:E632.

14. Kihara M, Yokomise H, Yamauchi A, et al. Spontaneous rupture of a parathyroid adenoma presenting as a massive cervical hemorrhage: report of a case. Surg Today 2001;31:222-4.

15. Hotes LS, Barzilay J, Cloud LP, Rolla AR. Spontaneous hematoma of a parathyroid adenoma. Am J Med Sci 1989;297:331-3.

16. Hellier WP, McCombe A. Extracapsular haemorrhage from a parathyroid adenoma presenting as a massive cervical haematoma. J Laryngol Otol 1997;111:585-7.

17. Ku P, Scott P, Kew J, van Hasselt A. Spontaneous retropharyngeal haematoma in a parathyroid adenoma. Aust N Z J Surg 1998;68:619-21.

18. Kihara M, Yokomise H, Yamauchi A, et al. Spontaneous rupture of a parathyroid adenoma presenting as a massive cervical hemorrhage: report of a case. Surg Today 2001;31:222-4.

19. Jougon J, Zénnaro O. Acute cervico-mediastinal hematoma of parathyroid origin. Ann Chir 1994;48:867-9.

20. Kataoka K, Taguchi M, Takeshita A, et al. Recurrence of primary hyperparathyroidism following spontaneous remission with intracapsular hemorrhage of a parathyroid adenoma. J Bone Miner Metab 2008;26:295-7.

21. Weber AL, Randolph G, Aksoy FG. The thyroid and parathyroid glands. CT and MR imaging and correlation with pathology and clinical findings. Radiol Clin N Am 2000;38:1105-29.

22. Gritzmann N, Koischwitz D, Rettenbacher T. Sonography of the thyroid and parathyroid glands. Radiol Clin N Am 2000;38:1131-45. 